\title{
Prospective case-series analysis of haematological malignancies in goldmining areas in South Africa
}

\author{
A M N Danjou, ${ }^{1} \mathrm{PhD} ;$ M Patel, ${ }^{2} \mathrm{PhD} ;$ C Espina, ${ }^{1} \mathrm{PhD} ;$ A Pentz,,${ }^{3,4} \mathrm{BSc} ;$ M Joffe,${ }^{3,4} \mathrm{MSc} ;$ F Winde,${ }^{5} \mathrm{PhD} ; \mathrm{J} \mathrm{Schüz},{ }^{1} \mathrm{PhD}$ \\ ${ }^{1}$ Section of Environment and Radiation, International Agency for Research on Cancer (IARC/World Health Organization), Lyon, France \\ ${ }^{2}$ Clinical Haematology Division, Department of Medicine, Chris Hani Baragwanath Academic Hospital and Faculty of Health Sciences, \\ University of the Witwatersrand, Johannesburg, South Africa \\ ${ }^{3}$ MRC/Wits Development Pathways for Health Research Unit, Department of Paediatrics, Faculty of Health Sciences, University of the \\ Witwatersrand, Johannesburg, South Africa \\ ${ }^{4}$ Non-communicable Diseases Research Division, Wits Health Consortium, Faculty of Health Sciences, University of the Witwatersrand, \\ Johannesburg, South Africa \\ ${ }^{5}$ Mine Water Research Group, Geography and Environmental Studies, Faculty of Natural and Agricultural Sciences, North-West University, \\ Vanderbijlpark, South Africa
}

Corresponding author: A M N Danjou (danjoua@fellows.iarc.fr)

\begin{abstract}
Background. South Africa (SA) has a long history of goldmining that has resulted in locally high levels of environmental contamination from uranium and its decay products (radium-226 and radon-222) from the mine tailings. Populations living around mine tailings of the Witwatersrand goldfields may be exposed through various pathways, raising concern about potential health risks associated with haematological malignancies (HMs), for which evidence is inconclusive.

Objectives. We designed a prospective case-series study of HMs at Chris Hani Baragwanath Academic Hospital (CHBAH), Johannesburg, the major public hospital in the area, to describe demographic and clinical characteristics, lifetime residential history and potential environmental uranium exposure pathways.

Methods. All patients, male and female, aged $\geq 18$ years and newly diagnosed with any form of leukaemia, lymphoma or myeloma at the CHBAH Haematology Unit in 2014 and 2015 were considered for inclusion in the study. Information on uranium exposure pathways and lifetime residential history was recorded from interviewer-administered questionnaires. These characteristics were described overall and according to subtypes of HM.

Results. Of 556 patients with HMs diagnosed in 2014 and 2015 at CHBAH, 189 patients aged 18 - 90 years were interviewed, mainly with non-Hodgkin's lymphoma (NHL) (37.6\%), leukaemia (32.8\%) and Hodgkin's lymphoma (HL) (13.8\%). HIV status was positive for 39.2\% of the patients, mostly with NHL and HL. Potential environmental uranium exposure pathways were identified. Working on goldmines was reported by 12 patients (6.3\%). Consumption of soil (geophagia) was a habit of 51 patients (27.0\%), particularly during pregnancy. Drinking water was mainly piped water $(76.6 \%$ in childhood and $97.9 \%$ in adulthood). Animal products and vegetables were most frequently obtained from stores ( $82.0 \%$ and $68.7 \%$, respectively, in childhood and $96.3 \%$ and $83.6 \%$ in adulthood). Patients were referred to CHBAH by government clinic doctors (44.4\%), referral hospitals (24.3\%) and private doctors (20.1\%). Most participants had been born and lived in Gauteng Province and Soweto ( $94.7 \%$ and $58.2 \%$, respectively), and reported two lifetime places of residence on average and living at their current residence for $\geq 20$ years $(49.2 \%)$.

Conclusions. We identified potential environmental uranium exposure pathways (occupational, lifestyle related and domestic) among patients with HMs that could have resulted in increased uranium exposure. HIV is common among patients with HMs. Together with the results from a previous retrospective case series of HMs at CHBAH (2004 - 2013), our findings suggest that further research on environmental uranium exposure in mining areas and $\mathrm{HM}$ risk in residents is warranted.
\end{abstract}

S Afr Med J 2019;109(5):340-346. DOI:10.7196/SAMJ.2019.v109i5.13538

South Africa (SA) has a long history of goldmining and milling, and it has been estimated that as an unwanted side product 100000 tons of uranium were contained in mine tailing deposits in the two goldfields in the Witwatersrand basin. ${ }^{[1]}$ Locally high levels of environmental contamination from uranium and its decay products, clearly linked to mining activity, have consequently been reported in water, soil, sediment and dust, reaching between 50 and 100 times the background levels. ${ }^{[1,2]}$ This situation has raised concern about long-term health risks, including cancer, associated with chronic environmental uranium exposure. ${ }^{[1]}$

Uranium is a natural and dense metal widespread in the environment and consists of three isotopes (234U, $325 \mathrm{U}$ and $238 \mathrm{U})$ that emit alpha- and beta-radiation. ${ }^{[3]}$ Uranium decay products include radium-226 and radon-222, which are also radioactive elements. In 2009, the International Agency for Research on Cancer (IARC) classified alpha- and beta-particle emitters as carcinogenic to humans (group 1), in particular radium-226, with sufficient evidence for bone sarcoma and carcinoma of the paranasal sinus and mastoid process, and radon-222, with sufficient evidence for lung cancer. ${ }^{[3,4]}$ Associations between uranium and its decay products and risk of haematological cancers have been hypothesised, although evidence is inconclusive. ${ }^{[5]}$ Positive associations have been observed for cumulative radon exposure and risk of leukaemia in cohorts of uranium miners, ${ }^{[3,6]}$ for radium-226 concentration in groundwater 
supplies and leukaemia incidence, ${ }^{[7]}$ and for uranium concentration in drinking water and non-Hodgkin's lymphoma (NHL) incidence. ${ }^{[8]}$ However, other studies did not find increased risks of haematological cancers associated with uranium, radium or radon exposure. ${ }^{[9-12]}$

Populations living in the vicinity of mine tailings of the Witwatersrand goldfields in SA may be exposed to uranium and its decay products from the tailings through various pathways, including drinking of contaminated water, ingestion of foodstuffs grown in contaminated areas, and inhalation of dust. Direct consumption of soil represents another exposure pathway, either intentionally (geophagia, prevalent among pregnant women) or unintentionally (hand-to-mouth contact between children). ${ }^{[13,14]}$ To our knowledge, no epidemiological study has ever been conducted among the exposed populations living around the tailings in relation to cancer risk. In 2013, a workshop focusing on research into environmental radiation exposure resulting from mining activities and risk of radiationrelated cancers in SA recommended conducting pilot studies to describe the populations living around mine tailings, pointing out the importance of understanding cancer referral patterns and subjects' mobility, the feasibility of recording residential histories, and the collection of factors that may modify cancer risk (e.g. HIV status). ${ }^{[15]}$

\section{Objectives}

This article reports the second, prospective, component of a case-series study of haematological cancer patients at Chris Hani Baragwanath Academic Hospital (CHBAH), SA. Our objectives were to describe the demographic and clinical characteristics and spatial distribution of patients newly diagnosed with a haematological malignancy (HM) and to assess the feasibility of collecting additional information on potential environmental uranium exposure pathways via interviewer-administered questionnaires. The case-series study also aimed to contribute to inform on whether a cancer epidemiological study on the association between environmental uranium exposure and haematological cancer risk is feasible in this setting.

\section{Methods \\ Participants and study design}

We analysed data from a 2-year prospective case-series study of HMs conducted at CHBAH in Soweto, Johannesburg. CHBAH is a tertiary public hospital, the largest in sub-Saharan Africa, serving the inhabitants of Soweto and others living in the Western, Far Western and Central basins and receiving patients from referral hospitals up to $150 \mathrm{~km}$ away. All patients, male and female, aged $\geq 18$ years and newly diagnosed with any form of leukaemia, lymphoma or myeloma at the Haematology Unit in 2014 and 2015 were considered for inclusion in the study, after signing an informed consent form. Participants were asked to complete a second informed consent to access their HIV status, which is routinely collected at the clinic. Individuals who did not agree to give access to their HIV status were still included in the study. The study was approved by the University of the Witwatersrand Human Research Ethics Committee (ref. no. M140256) and the IARC Ethics Committee (ref. no. 14-19).

\section{Data collection}

Information on clinical characteristics (date of diagnosis, histology, stage and site) was extracted from outpatient and inpatient files. The diagnoses were coded according to the ICD-O-3 (International Classification of Disease for Oncology, 3rd edition ${ }^{[16]}$ ) and grouped into five broad disease categories: Hodgkin's lymphoma (HL), NHL, leukaemia, myeloma and myelodysplastic/myeloproliferative neoplasm (MDS/MPN). HIV status was ascertained from records of consenting participants. A structured questionnaire was administered to the participants by a trained study nurse during routine clinical visits at $\mathrm{CHBAH}$; study investigators provided oversight to ensure the quality of data collection. Data collected comprised sections on demographic factors (gender, date of birth and ethnicity), current residence (complete address and geographical information system (GIS) co-ordinates) and housing characteristics, residential history (district, city, province and country) for five age periods (birth, 0 14 years, 15 - 29 years, 30 - 44 years, and 45 years to present), sources of drinking water and food for two age periods (childhood: 0 14 years and adulthood: 15 years to present), geophagia, education, brief occupational history including items on the mining industry, and other cancer risk factors (tobacco and radiation). Sequential study numbers were assigned to each record to be used as anonymised study ID.

\section{Statistical analysis}

Questionnaire data were merged with clinical information. Descriptive analyses were performed to describe the distribution of factors such as sources of drinking water and food, housing characteristics, residential history, smoking, soil consumption, work history on mines and referral patterns, overall and by subtypes of HMs, using means and standard deviations (SDs) for continuous covariates and frequencies and percentages for categorical covariates.

Data analysis was performed at the IARC (Lyon, France) with anonymised data, using SAS statistical software version 9.3 (SAS Institute, USA).

\section{Results}

\section{General and clinical characteristics}

A total of 556 haematological cancer patients were diagnosed at CHBAH in 2014 and 2015, mainly with NHL (44.8\%), followed by leukaemia (24.5\%), HL (14.0\%), myeloma (12.2\%) and MDS/MPN (4.5\%). The most common histological subtypes of NHL were diffuse large B-cell lymphoma (36.5\%), Burkitt's lymphoma (BL) (12.7\%) and plasmablastic lymphoma (12.3\%). Of the 556 haematological cancer patients, 200 were interviewed (36.0\%). Reasons for the low number of interviewed patients included refusals, that many patients, who may have been inpatients, were too ill to be interviewed, and that some of them subsequently died and were therefore not interviewed. In addition, after their initial diagnosis and discharge some patients may not have returned for further follow-up to the outpatient clinic, where it was easier to interview patients. Of those interviewed, we excluded 4 patients who were already registered in a previous retrospective case-series study conducted over the period 2004 $2013^{[17]}$ and 7 for whom a diagnosis could not be confirmed. The final study sample comprised 189 eligible patients.

Participants were aged 18 - 90 years at diagnosis, and were mostly from black African ethnic groups (35.5\% Zulu, 19.6\% Sotho, 10.6\% Xhosa and $13.8 \%$ others). There were more male than female participants (gender ratio 1.1 males to females). With regard to tobacco smoking habits, $38.1 \%$ of participants had ever smoked for at least 6 months and $9.7 \%$ of them were current smokers at the time of the interview. Eight patients (4.2\%) had received radiation treatment for a prior malignancy and 186 (98.4\%) had ever had a scan, including X-ray, computed tomography scan and magnetic resonance imaging scan. All participants consented to give access to their HIV status; $39.2 \%$ were HIV-positive (Table 1).

NHL was the most frequent cancer diagnosed in the study population $(37.6 \%)$, followed by leukaemia $(32.8 \%)$, HL (13.8\%) 
Table 1. Demographic, clinical and uranium-related exposure characteristics of patients from the prospective case series of haematological malignancies at CHBAH, SA, 2014 and 2015

\begin{tabular}{|c|c|}
\hline & Haematological cancer patients $(N=189), n(\%)$ \\
\hline \multicolumn{2}{|l|}{ Demographic and clinical information } \\
\hline \multicolumn{2}{|l|}{ Gender } \\
\hline Male & $98(51.9)$ \\
\hline Female & $91(48.1)$ \\
\hline \multicolumn{2}{|l|}{ Age at diagnosis (years) } \\
\hline $18-30$ & $27(14.3)$ \\
\hline $31-40$ & $53(28.0)$ \\
\hline $41-50$ & $27(14.3)$ \\
\hline $51-60$ & $40(21.2)$ \\
\hline$>60$ & $42(22.2)$ \\
\hline \multicolumn{2}{|l|}{ Tumour histology } \\
\hline NHL & $71(37.6)$ \\
\hline Leukaemia & $62(32.8)$ \\
\hline $\mathrm{HL}$ & $26(13.8)$ \\
\hline Myeloma & $25(13.2)$ \\
\hline MDS/MPN & $5(2.7)$ \\
\hline \multicolumn{2}{|l|}{ HIV status } \\
\hline Negative & $115(60.8)$ \\
\hline Positive & $74(39.2)$ \\
\hline \multicolumn{2}{|l|}{ Smoking status } \\
\hline Never smoker & $117(61.9)$ \\
\hline Ever smoker & $72(38.1)$ \\
\hline Current smoker & $19(10.1)$ \\
\hline Ever received radiation treatment for cancer & $8(4.2)$ \\
\hline \multicolumn{2}{|l|}{ Duration of radiation treatment (days) } \\
\hline $1-20$ & $2(1.1)$ \\
\hline $21-30$ & $3(1.6)$ \\
\hline Do not know & $3(1.6)$ \\
\hline Ever had a radiation scan & $186(98.4)$ \\
\hline \multicolumn{2}{|l|}{ Type of radiation scan ${ }^{*}$} \\
\hline X-ray only & $49(25.9)$ \\
\hline CT scan only & $7(3.7)$ \\
\hline $\mathrm{X}$-ray and CT scan & $116(61.4)$ \\
\hline $\mathrm{X}$-ray and MRI scan & $5(2.6)$ \\
\hline CT scan and MRI scan & $1(0.5)$ \\
\hline $\mathrm{X}$-ray, CT scan and MRI scan & $8(4.2)$ \\
\hline Ever worked with radiation & $1(0.5)$ \\
\hline \multicolumn{2}{|l|}{ Potentially uranium-related exposure characteristics } \\
\hline Ever craved and ate soil & $51(27.0)$ \\
\hline \multicolumn{2}{|l|}{ Source of soil for consumption ${ }^{*}$} \\
\hline Own/neighbour's/relative's yard & $27(14.3)$ \\
\hline Purchased from store & $4(2.1)$ \\
\hline Purchased from roadside vendors & $28(14.8)$ \\
\hline \multicolumn{2}{|l|}{ Time periods of soil consumption } \\
\hline Childhood & $14(7.4)$ \\
\hline Adulthood & $31(16.4)$ \\
\hline Childhood and adulthood & $6(3.2)$ \\
\hline Pregnancy & $19(10.1)$ \\
\hline \multicolumn{2}{|l|}{ Sources of water for drinking or cooking* } \\
\hline \multicolumn{2}{|l|}{ During childhood } \\
\hline Piped water (tap) & $145(76.6)$ \\
\hline Borehole & $16(8.5)$ \\
\hline Well & $14(7.4)$ \\
\hline River & $22(11.7)$ \\
\hline
\end{tabular}

Continued ... 
Table 1. (continued) Demographic, clinical and uranium-related exposure characteristics of patients from the prospective case series of haematological malignancies at CHBAH, SA, 2014 and 2015

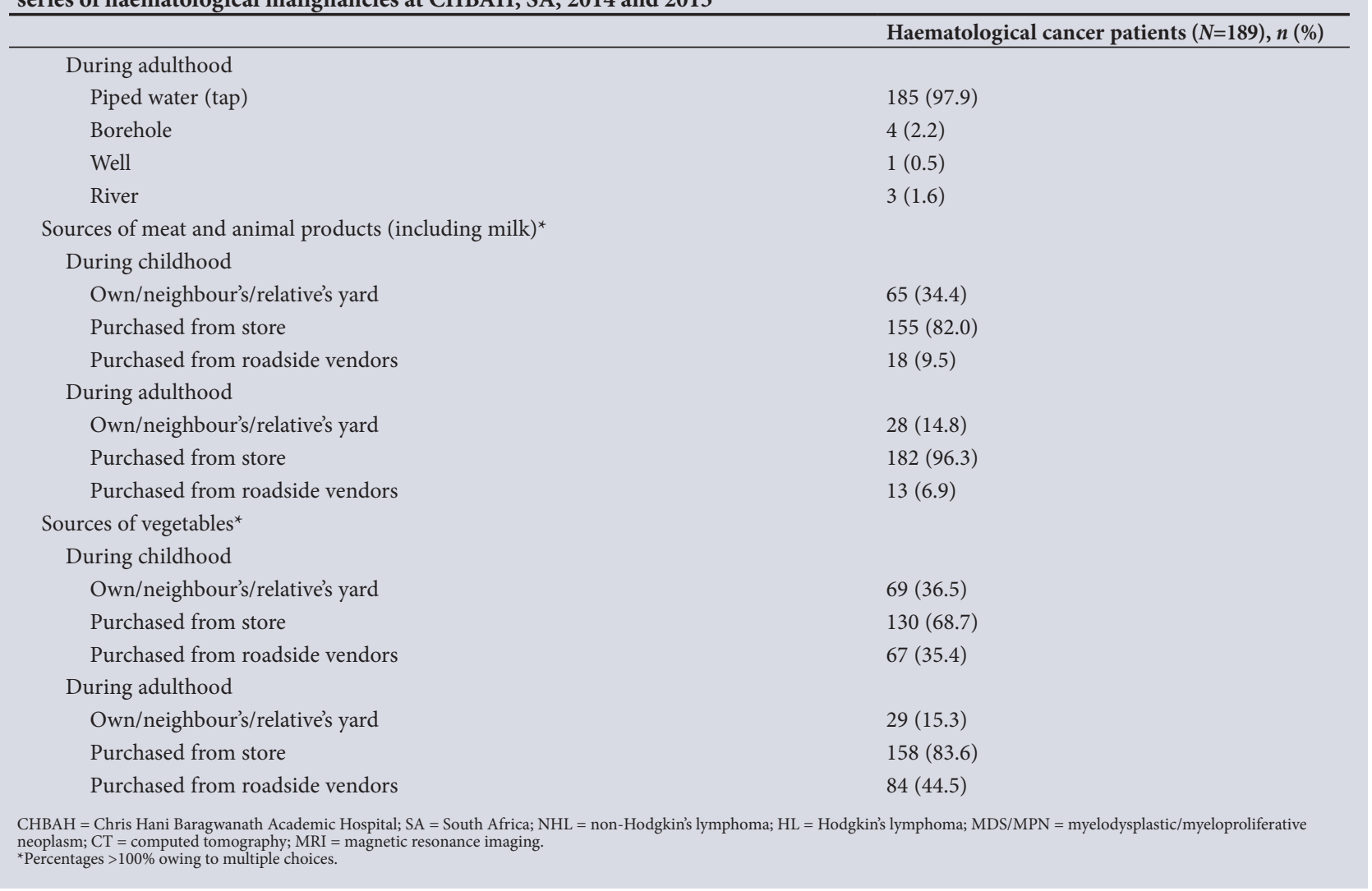

and myelomas (13.2\%). Overall, $14.3 \%$ of participants were aged 18 - 30 years at diagnosis, and $43.4 \%$ were aged $\geq 51$ years (Table 1 ). HIV status varied according to tumour histology, with $70.4 \%$ of patients with NHL and 53.9\% with HL being HIV-positive. Whereas the distribution of diagnoses among women did not differ from the overall distribution, men were more frequently diagnosed with NHL (39.8\%), followed by leukaemia (33.7\%), myeloma (13.3\%), HL (10.2\%) and MPN/MDS (3.1\%). Leukaemia was most commonly diagnosed among participants aged 18 - 30 years and $>60$ years $(25.8 \%$ and $27.4 \%$, respectively). The proportion of myelomas increased with age and was highest in participants aged $>60$ years. HL and NHL were most frequently diagnosed in participants aged $31-60$ years. The majority of NHL subtypes were diffuse large B-cell lymphoma (DLBCL) (40.8\%), and several cases of BL (19.7\%) and plasmablastic lymphoma (PBL) (14.1\%) were reported. Participants diagnosed with these subtypes were also predominantly HIV-positive: $75.9 \%$ of DLBCL, $100 \%$ of BL and $100 \%$ of PBL. Similarly, high proportions of participants with HL, i.e. $54.6 \%$ of mixed-cellularity (MC), $37.5 \%$ of nodular sclerosis (NS) and $33.3 \%$ of lymphocyte-depleted (LD) subtypes, were HIV-positive. Acute myeloid leukaemia accounted for $45.2 \%$ of cases of leukaemia, followed by chronic myelogenous leukaemia (24.2\%), chronic lymphocytic leukaemia (19.4\%) and acute lymphoblastic leukaemia (11.3\%).

\section{Potentially uranium-related exposure characteristics}

Of the 189 patients with haematological cancers, 12 (6.3\%) reported having worked on mines, for time periods ranging from 1 month to 18 years. They were all men and were diagnosed with leukaemia $(n=5)$, myeloma $(n=3)$, NHL $(n=3)$ and MDS/MPN $(n=1)$. All of them had worked on goldmines and 2 had also worked on coal mines and platinum mines. However, some mine workers had been assigned to clerical, cleaning or security tasks ( $n=4,33.3 \%)$.

Craving and eating soil was a habit of 51 participants (27.0\%), mostly women $(n=40,78.4 \%)$ (Table 1$)$. The main sources of soil for consumption were roadside vendors and yards $(41.2 \%$ and $39.2 \%$, respectively), while a few individuals purchased soil from stores (5.9\%). Soil consumption occurred more frequently during adulthood than childhood (60.8\% v. $27.5 \%)$, and 19 women (47.5\%) had consumed soil during pregnancy. The distribution of diagnoses among soil consumers did not differ from the overall distribution.

The main source of water for drinking and cooking was piped (tap) water during both childhood and adulthood (76.6\% and $97.9 \%$, respectively). Other sources of water reported by the participants were borehole $(8.5 \%$ and $2.2 \%)$, well $(7.4 \%$ and $0.5 \%)$ and river $(11.7 \%$ and $1.6 \%)$ water. The most frequent source of meat and animal products and vegetables was stores during both childhood and adulthood $(82.0 \%$ and $96.3 \%$, respectively, for meat and animal products and $68.7 \%$ and $83.6 \%$ for vegetables) (Table 1 ).

\section{Geographical characteristics and lifetime residential history}

Table 2 shows the residential characteristics, distance from the hospital and referral patterns of the participants. At the time of the interview all were living in SA, particularly in Gauteng Province (94.7\%), in Soweto (58.2\%), Vereeniging (9.0\%), Johannesburg (8.5\%) and other cities/towns (24.3\%); the rest were from the provinces of North West, Free State and Mpumalanga (5.2\%). Approximately half of the respondents reported having lived in their current residence for $\geq 20$ years $(49.2 \%)$, including $24.9 \%$ for $\geq 35$ years. Patients were mainly referred to $\mathrm{CHBAH}$ by government clinic doctors 


\begin{tabular}{|c|c|}
\hline & $\begin{array}{l}\text { Haematological } \\
\text { cancer patients } \\
(N=189), n(\%)\end{array}$ \\
\hline \multicolumn{2}{|c|}{ Province at time of interview } \\
\hline Gauteng & $179(94.7)$ \\
\hline North West & $8(4.2)$ \\
\hline Free State & $1(0.5)$ \\
\hline Mpumalanga & $1(0.5)$ \\
\hline \multicolumn{2}{|c|}{ Main place at time of interview } \\
\hline Soweto & $110(58.2)$ \\
\hline Johannesburg & $16(8.5)$ \\
\hline Vereeniging & $17(9.0)$ \\
\hline Lenasia & $5(2.6)$ \\
\hline Heidelberg & $4(2.1)$ \\
\hline Krugersdorp & $2(1.1)$ \\
\hline Vanderbijlpark & $3(1.6)$ \\
\hline Other & $32(16.9)$ \\
\hline \multicolumn{2}{|c|}{ Years at residence at time of interview } \\
\hline$<1$ & $7(3.7)$ \\
\hline $1-<10$ & $44(23.3)$ \\
\hline $10-<20$ & $45(23.8)$ \\
\hline$\geq 20$ & $93(49.2)$ \\
\hline \multicolumn{2}{|c|}{ Type of transport to CHBAH } \\
\hline Taxi & $104(55.0)$ \\
\hline Own vehicle & $53(28.0)$ \\
\hline Bus & $10(5.3)$ \\
\hline Other ${ }^{*}$ & $22(11.6)$ \\
\hline \multicolumn{2}{|c|}{ Travel time to CHBAH (hours) } \\
\hline$<1$ & $145(76.7)$ \\
\hline $1-<2$ & $32(16.9)$ \\
\hline$\geq 2$ & $12(6.3)$ \\
\hline \multicolumn{2}{|l|}{ Referral to CHBAH } \\
\hline Government clinic & $84(44.4)$ \\
\hline Referral hospital & $46(24.3)$ \\
\hline Private doctor & $38(20.1)$ \\
\hline Other $^{\dagger}$ & $21(11.1)$ \\
\hline
\end{tabular}

(44.4\%), referral hospitals (24.3\%) or private doctors (20.1\%). Those referred to $\mathrm{CHBAH}$ by another hospital were mostly diagnosed with leukaemia (60.9\%), followed by NHL (26.1\%), myeloma (8.7\%), HL (2.2\%) and MDS/MPN (2.2\%). Most respondents were living $<1$ hour from $\mathrm{CHBAH}(76.7 \%)$ and using taxis $(55.0 \%)$, their own vehicle (28.0\%) or an ambulance (10.1\%) to get to CHBAH.

Lifetime residential history from birth to 29 years of age was available for all 189 respondents, from 30 to 44 years of age for $161 / 189$ ( $85.2 \%$, total 165 respondents) and from 45 years to the present for $95 / 189$ (50.3\%, total 97 respondents). The mean (SD) number of different places of residence reported for the five age periods was 2.1 (1.0) per respondent; 30.7\% of respondents reported only one lifetime place of residence, $40.7 \%$ two places and the remainder three to five places. Of the participants reporting one lifetime place of residence, $67.2 \%$ were living in Gauteng and 51.7\% in Soweto. Lifetime geographical distribution by country showed that most respondents had been born and lived in SA, particularly in Gauteng Province and Soweto, and the proportion of respondents living in SA and Gauteng increased with age periods $(92.6 \%$ and $52.4 \%$, respectively, at birth and $96.9 \%$ and $88.7 \%$ at $\geq 45$ years of age). The remaining respondents had been born and lived in Zimbabwe, Mozambique, Lesotho and the Democratic Republic of the Congo before coming to SA.

\section{Discussion}

In our study population, when classifying diagnoses into broad clinical categories, NHL was the most frequent haematological cancer diagnosed during the study period 2014 and 2015, followed closely by leukaemia. The distribution of diagnoses is comparable to that for all haematological cancers prospectively diagnosed at $\mathrm{CHBAH}$ during the same period $(N=556)$, although there were fewer cases of NHL in our study population (37.6\% v. $44.8 \%)$, which may be due to the poor prognosis of NHL, resulting in a lower number of NHL patients interviewed. Moreover, our results are similar to those from a previous retrospective case-series study at $\mathrm{CHBAH},{ }^{[17]}$ as well as studies in the Eastern Cape Province ${ }^{[18]}$ and at national level with data from the South African National Cancer Registry. ${ }^{[19]}$

HIV status was available for all our participants, as testing has become a routine procedure at the clinic and no patient refused to give access to their HIV status; $39.2 \%$ of participants were HIV-positive. The prevalence of HIV infection in SA was estimated at $11.2 \%$ in 2015. ${ }^{[20]}$ This difference in prevalence estimates can be explained by the role of infections in the aetiology of HMs. NHL has been recognised as an AIDS-defining malignancy, in particular for some specific subtypes, including BL, DLBCL and PBL. ${ }^{[21]} \mathrm{A}$ previous study conducted at CHBAH showed an increase in NHL frequency in HIVpositive individuals between 1993 and 2012. ${ }^{[22]}$ In addition, previous studies have observed positive associations with HL in HIV-positive patients. ${ }^{[21,23,24]}$ Our results are in agreement with these findings, as most patients with NHL and HL (in particular DLBCL, BL and $\mathrm{PBL}$, and MC and NS subtypes) were HIV-positive. Moreover, in the overall population of patients with HMs prospectively diagnosed at CHBAH in 2014 and 2015, the rate of HIV seropositivity was highest among those with NHL and HL (70.4\% and 53.9\%, respectively). These results show that it is essential to collect information on HIV and other infectious diseases along with diagnosis, as well as on subtypes of HMs, in order to identify infection-related malignancies and understand the burden of HMs in this population. ${ }^{[25]}$

In our study population overall, HMs occurred more frequently in males than in females, as was seen over the 2004 - 2013 time period at $\mathrm{CHBAH}^{[17]}$ and in other studies conducted in SA, ${ }^{[18]}$ in Europe ${ }^{[26,27]}$ and worldwide. ${ }^{[28]}$ However, we observed gender differences in types of HM, as HL was more frequently diagnosed among women than men. This differs from the studies listed above, ${ }^{[18,26-28]}$ in which all haematological cancers were more frequent in men than in women, and with the previous findings at $\mathrm{CHBAH},{ }^{[17]}$ in which myeloma affected more women than men. In addition, age distribution differed across diagnoses: leukaemia was most commonly diagnosed in young participants and myeloma in participants aged over 60 years, the proportion of HL increased with age until 40 years and then decreased, and the proportion of NHL peaked at $31-40$ years and then decreased after 60 years. This corresponds to the patterns observed in SA. ${ }^{[17-19]}$ Moreover, $38.1 \%$ of participants had ever smoked for at least 6 months and some had been exposed to radiation through cancer treatment (4.2\%) and scans (98.4\%). These findings confirm the relevance of recording individual potentially confounding lifestyle factors such as smoking and radiation. 
Questionnaires were administered to our study participants by trained interviewers, and overall the information collected on uraniumrelated exposure pathways was complete. Working on mines was reported by $6.3 \%$ of the participants, although some participants' tasks were not related to mine working (clerical, cleaning and security). In SA, mining of gold and uranium ore represents $21 \%$ of the mining industry, and the number of direct employees in the goldmining industry was 105000 in 2015. ${ }^{[29,30]}$ Although a small proportion of participants in our study reported working on mines, the proportion of men and women occupationally exposed to uranium through goldmine work may therefore not be negligible in larger populations, confirming that investigating uranium exposure requires assessment of occupational exposure of the population living in mining areas, and that it is necessary to collect further information on specific tasks related to and duration of mine work. ${ }^{[17]}$

In populations living in mining areas, consumption of contaminated soil is a suspected pathway for uranium exposure. Soil consumption (geophagia) is the deliberate consumption of earth in the form of soil and clay. This habit is practised worldwide and is common in southern Africa. ${ }^{[31]}$ Reasons for geophagia include cultural and religious beliefs, medicinal purposes and mineral deficiency, but it may have health complications such as iron deficiency anaemia, lead poisoning and lack of nutrients in the diet. ${ }^{[32]}$ Geophagia was practised by nearly a third of our study population, mostly women, and was particularly prevalent among pregnant women. Studies on geophagia in various SA female populations have reported prevalence estimates ranging from $54 \%$ in a survey of pregnant women taking antenatal classes at a clinic on the border of Gauteng and North West provinces $^{[33]}$ to $75 \%$ in a rural area of the Eastern Cape. ${ }^{[34]}$ Our figure, although lower because our subjects did not comprise only pregnant women, shows that geophagia is not a negligible factor in the assessment of uranium exposure pathways. The study participants consumed soil from their own yards (or neighbours' or relatives' yards) and from roadside vendors. If the sources of soil are located in the vicinity of mine tailings, it could potentially have elevated concentrations of uranium and radium. Future studies should collect detailed information to properly assess uranium exposure due to geophagia, such as the frequency and quantity of soil ingested, as well as baking methods and selling of mine tailing cookies. ${ }^{[33]}$

Drinking and consumption of contaminated water and food are thought to be potential pathways for uranium exposure. ${ }^{[1,35]}$ Although 77 - $98 \%$ of our participants had drunk piped water during both childhood and adulthood, some also drank borehole water $(8.5 \%$ during childhood and $2.2 \%$ as adults), well water $(7.4 \%$ and $0.5 \%)$ and river water $(11.7 \%$ and $1.6 \%)$. While these proportions were not negligible during childhood, we noted that drinking of piped water increased to nearly $100 \%$ in adulthood, with a corresponding decrease in drinking of borehole, well and river water. In the Witwatersrand goldfields, the mine tailings are the largest source of uranium water pollution. ${ }^{[1]}$ Government reports have confirmed that not only are many rivers and streams in goldmining areas contaminated by uranium, including streams used by residents for domestic activities such as drinking and cooking, but some tap water in downstream municipalities is also affected. ${ }^{\left[{ }^{86-38]}\right.}$ Moreover, a study established a geostatistical association between elevated uranium concentrations in untreated borehole water consumed by farmers and the occurrence of haematological abnormalities (serving as a proxy for leukaemia) ${ }^{[35,39]}$ Other studies have demonstrated that drinking of uranium-contaminated water was associated with increased incidences of leukaemia in several counties in Florida, USA, ${ }^{[7]}$ and with NHL in Canada ${ }^{[8]}$ Our study participants reported that most of the vegetables and animal products they consumed were purchased from stores, therefore without their knowing the location of the production sites, while lower proportions came from their yards (or neighbours' or relatives' yards). Vegetables, animals and fish may be contaminated by uranium through contaminated soil and water, and then consumed by the population. These findings indicate that uranium exposure from drinking water and food consumption habits should be investigated in the populations living in the vicinity of goldmining tailings, and furthermore that measurement data should be coupled with questionnaires on water and food consumption. ${ }^{[5]}$

Lifetime residential history was recorded in the study, participants reporting the place of residence in which they had spent most time for five age periods. Lifetime residential mobility was generally low, with $30.7 \%$ and $40.7 \%$ of participants reporting one and two places of residence, respectively, and approximately half having lived in their current residence for $\geq 20$ years. The vast majority of participants were living in Soweto, in Gauteng - including participants who reported one or two lifetime places of residence - where uranium concentrations from goldmine tailings were recently found to be higher than recommended safe limits. ${ }^{[40]}$ Although the information on lifetime residential history was complete, street names and postal codes were not recorded or did not exist. As a consequence, GIS co-ordinates were not available and the residential history of participants could not be geocoded with accuracy. In future studies investigating environmental uranium exposure, the location of residence of the participants should be collected in a way that would allow determination of the GIS co-ordinates and associate residential data with environmental exposure data.

\section{Study limitations and strengths}

Our study has some limitations. First, as GIS co-ordinates were not recorded along with the residential history, geocoding of the lifetime places of residence of the participants could not be performed. Second, the fact that participants had various referral patterns to $\mathrm{CHBAH}$, including referral from other hospitals, may have led to inconsistencies in addresses reported as it was observed in the previous retrospective case series that some participants gave a temporary residence such as a referral hospital, hostel, nursing home or prison instead of their permanent place of residence. ${ }^{[17]}$ However, the active recruitment of cases may have avoided claiming of incorrect residential addresses.

Strengths of our study include the prospective recruitment and the number of haematological cancer patients at $\mathrm{CHBAH}$, the description of the burden of HMs in a population living in mining areas, and the collection of lifetime residential history. To our knowledge, this is the first attempt to describe potential environmental uranium exposure pathways in a population living in goldmining areas in SA. The recruitment of the cases at a tertiary hospital (CHBAH) further allowed us to obtain information on participants' HIV status, which would not have been accessible from the National Cancer Registry. ${ }^{[19]}$ All the above factors appear to be relevant in the investigation of environmental uranium exposure and risk of haematological cancer. Estimation of environmental lifetime exposure in future studies should be facilitated by the stability of residential history in the area, as we found that many of our respondents had lived in the same place for over 20 years.

\section{Conclusions}

Together with the results from the retrospective case-series analysis of HMs, our study confirmed that a large number of participants can be recruited through the Haematology Unit at CHBAH. ${ }^{[17]}$ Overall, participants were willing to give access to their HIV results and to complete the questionnaire. We identified several pathways for 
potential environmental uranium exposure in our study population, including occupation as mine workers, geophagia, drinking of nonbottled water and consumption of vegetables and animal products grown in the vicinity of mine tailings, which could be related to increased uranium exposure. The active recruitment of participants allowed us to collect their lifetime residential history, which showed low residential mobility in our study population, although detailed information on the residences' locations will be needed in further studies to geocode patients' residential history with GIS co-ordinates and apply it in a virtual geographical environment (VGE). The GIS and VGE data may provide, in addition to levels of uranium and its decay products in water, soil, air and biota, a detailed mapping of uranium exposure pathways and patterns. ${ }^{[41]}$ Our findings suggest that further research on environmental uranium exposure in mining areas and HM risk using traditional epidemiological designs is feasible.

\section{Declaration. None.}

Acknowledgements. We are grateful to the study participants and the interviewers. Dr Sara Schonfeld and Dr Tomoko Inamasu started this work while working at the IARC and therefore contributed to the design and conduct of the study.

Author contributions. AMND analysed and interpreted the data and drafted the manuscript. MP contributed to the acquisition and interpretation of the data, and helped draft the manuscript and revise it critically for important intellectual content. CE helped interpret the data, draft the manuscript and revise it critically for important intellectual content. AP contributed to the data extraction from medical files. MJ contributed to the acquisition of the data, supervised the data extraction and helped draft the manuscript. FW contributed to the interpretation of the data and helped draft the manuscript and revise it critically for important intellectual content. JS conceived the study, contributed to interpretation of the data, and helped draft the manuscript and revise it critically for important intellectual content. All authors read and approved the final manuscript.

Funding. The study was supported by a grant made to the IARC by the Ministry of Health, Labour and Welfare of Japan (grant agreement no. 2012-02-21-01). The funding source had no involvement in the content or preparation of the manuscript.

Conflicts of interest. None.

Disclaimer. Where authors are identified as personnel of the International Agency for Research on Cancer/World Health Organization, the authors alone are responsible for the views expressed in this article and they do not necessarily represent the decisions, policy or views of the International Agency for Research on Cancer/World Health Organization.

1. Winde F. Uranium pollution of the Wonderfonteinspruit, 1997 - 2008. Part 1: Uranium toxicity regional background and mining-related sources of uranium pollution. Water SA 2010;36(3):239-256. http://www.scielo.org.za/scielo.php?script=sci_arttext\&pid=\$1816-79502010000300006\&lng=en\&nr $\mathrm{m}=\mathrm{iso}$ (accessed 17 March 2019)

2. Barthel R. Radiological impact assessment of mining activities in the Wonderfonteinspruit catchment area, South Africa. In: Merkel B, Schipek M, eds. The New Uranium Mining Boom. Berlin: Springer, 2011:517-527. https://doi.org/10.1007/978-3-642-22122-4_60

3. International Agency for Research on Cancer. Personal Habits and Indoor Combustions. Vol. $100 \mathrm{E}$ : A Review of Human Carcinogens. IARC Monographs on the Evaluation of Carcinogenic Risks to Humans. Lyon: IARC, 2012. https://monographs.iarc.fr/wp-content/uploads/2018/06/monol00E.pdf Humans. Lyon: IARC, 2012.
(accessed 17 March 2019).

4. International Agency for Research on Cancer. Radiation. Vol. 100 D: A Review of Human Carcinogens. IARC Monographs on the Evaluation of Carcinogenic Risks to Humans. Lyon: IARC, 2012. https:// IARC Monographs on the Evaluation of Carcinogenic Risks to Humans. Lyon: IARC, 2012.
monographs.iarc.fr/wp-content/uploads/2018/06/mono100D.pdf (accessed 17 March 2019).

monographs.iarc.fr/wp-content/uploads/2018/06/mono 100D.pdf (accessed 17 March 2019).
5. Canu IG, Laurent O, Pires N, Laurier D, Dublineau I. Health effects of naturally radioactive water 5. Canu IG, Laurent O, Pires N, Laurier D, Dublineau I. Health effects of naturally radioactive water
ingestion: The need for enhanced studies. Environ Health Perspect 2011;119(12):1676-1680. https:// ingestion: The need for enhanced
doi.org/10.1289/ehp.1003224

6. Řerícha V, Kulich M, Keřicha R, Shore DL, Sandler DP. Incidence of leukemia, lymphoma, and multiple 6. Rericha V, Kulich M, Řericha R, Shore DL, Sandler DP. Incidence of leukemia, lymphoma, and multiple
myeloma in Czech uranium miners: A case-cohort study. Environ Health Perspect 2006;114(6):818myeloma in Czech uranium miners:
822. https://doi.org/10.1289/ehp.8476
7. Lyman GH, Lyman CG, Johnson W. Association of leukemia with radium groundwater contamination. JAMA 1985;254(5):621-626. https://doi.org/10.1001/jama.1985.03360050059026

8. Witmans MR, McDuffie HH, Karunanayake C, Kerrich R, Pahwa P. An exploratory study of chemical Witmans MR, McDuffie HH, Karunanayake C, Kerrich R, Pahwa P. An exploratory study of chemical
elements in drinking water and non-Hodgkin's lymphoma. Toxicol Environ Chem 2008;90(6):1227elements in drinking water and non-Hodgkin's lymph
1247. https://doi.org/10.1080/02772240801937370

9. Zablotska LB, Lane RSD, Frost SE, Thompson PA. Leukemia, lymphoma and multiple myeloma Zablotska LB, Lane RSD, Frost SE, Thompson PA. Leukemia, lymphoma and multiple myeloma
mortality $(1950$ - 1999) and incidence $(1969$ - 1999) in the Eldorado uranium workers cohort. Environ mortality (1950 - 1999) and incidence (1969 - 1999) in the Eldorado uran
Res 2014;130(April):43-50. https://doi.org/10.1016/j.envres.2014.01.002

10. Auvinen A, Kurttio P, Pekkanen J, Pukkala E, Ilus T, Salonen L. Uranium and other natural radionuclides in drinking water and risk of leukemia: A case-cohort study in Finland. Cancer Causes Control 2002;13(9):825-829. https://doi.org/10.1023/A:1020647704999

11. Seiler RL. Temporal changes in water quality at a childhood leukemia cluster. Ground Water 2004;42(3):446-455. https://doi.org/10.1111/j.1745-6584.2004.tb02692.x

12. Fuortes L, McNutt LA, Lynch C. Leukemia incidence and radioactivity in drinking water in 59 Iowa towns. Am J Public Health 1990;80(10):1261-1262. https://doi.org/10.2105/AJPH.80.10.1261

13. Mathee A, Naicker N, Kootbodien T, et al. A cross-sectional analytical study of geophagia practices and blood metal concentrations in pregnant women in Johannesburg, South Africa. S Afr Med J 2014;104(8):568-573. https://doi.org/10.7196/SAMJ.7466

14. Njiru H, Elchalal U, Paltiel O. Geophagy during pregnancy in Africa: A literature review. Obstet Gynecol Surv 2011;66(7):452-459. https://doi.org/10.1097/OGX.0b013e318232a034

15. Schonfeld SJ, Winde F, Albrecht C, et al. Health effects in populations living around the uraniferous gold mine tailings in South Africa: Gaps and opportunities for research. Cancer Epidemio 2014;38(5):628-632. https://doi.org/10.1016/..canep.2014.06.003

16. Fritz AG, ed. International Classification of Diseases for Oncology: ICD-O. 3rd ed, 1st rev. Geneva: World Health Organization, 2013.

17. Inamasu $\mathrm{T}$, Patel $\mathrm{M}$, Espina $\mathrm{C}$, et al. Retrospective case-series analysis of haematological malignancies in gold mining areas of South Africa. S Afr Med J 2018;108(10):858-864. https://doi.org/10.7196/ SAMJ.2018.v108i10.13175

18. Oelofse D, Truter I. Incidence of haematological malignancies, Eastern Cape Province, South Africa, 2004 - 2013. Cancer Epidemiol 2018;53(April):166-171. https://doi.org/10.1016/j.canep.2018.01.016

19. Schonfeld SJ, Erdmann F, Wiggill T, et al. Hematologic malignancies in South Africa 2000 - 2006 Schonfeld S,, Erdmann F, Wiggill T, et al. Hematologic malignancies in South Africa 2000 - 2006:
Analysis of data reported to the National Cancer Registry. Cancer Med 2016;5(4):728-738. https:// Analysis of data reported
doi.org/10.1002/cam4.597

20. Statistics South Africa. Mid-year population estimates, 2015. Statistical release P0302. Pretoria: Stats Statistics South Africa. Mid-year population estimates, 2015. Statistical release P0302. Pretoris.
SA, 2015. https://www.statssa.gov.za/publications/P0302/P03022015.pdf (accessed 5 May 2018)

21. International Agency for Research on Cancer Working Group on the Evaluation of Carcinogenic Risk to Humans. Human Immunodeficiency Viruses and Human T-Cell Lymphotropic Viruses. IARC to Humans. Human Immunodeficiency Viruses and Human T-Cell Lymphotropic Viruses. IARC
Monographs on the Evaluation of Carcinogenic Risks to Humans, No. 67. Lyon: IARC, 1996. https:/ Monographs on the Evaluation of Carcinogenic Risks to Humans, No.
www.ncbi.nlm.nih.gov/books/NBK419321/ (accessed 17 March 2019).

22. Patel M, Philip V, Omar T, et al. The impact of human immunodeficiency virus infection (HIV) on lymphoma in South Africa. J Cancer Ther 2015;06(06):527-535. https://doi.org/10.4236/jct.2015.66057 23. Stein L, Urban MI, O'Connell D, et al. The spectrum of human immunodeficiency virus-associate cancers in a South African black population: Results from a case-control study, 1995 - 2004. Int Cancer 2008;122(10):2260-2265. https://doi.org/10.1002/ijc.23391

24. Wiggill TM, Mantina H, Willem P, Perner Y, Stevens WS. Changing pattern of lymphoma subgroups a a tertiary academic complex in a high-prevalence HIV setting: A South African perspective. J Acquir Immune Defic Syndr 2011;56(5):460-466. https://doi.org/10.1097/QAI.0b013e31820bb06a

25. Wiggill TM, Mayne ES, Willem P. Challenges in lymphoma diagnosis in HIV positive patients in the South African setting. Transfus Apher Sci 2013;49(2):157-162. https://doi.org/10.1016/j. transci.2013.07.020

26. Smith A, Howell D, Patmore R, Jack A, Roman E. Incidence of haematological malignancy by sub-type: A report from the Haematological Malignancy Research Network. Br J Cancer 2011;105(11):16841692. https://doi.org/10.1038/bic.2011.450

27. Sant M, Allemani C, Tereanu C, et al. Incidence of hematologic malignancies in Europe by morphologic subtype: Results of the HAEMACARE project. Blood 2010;116(19):3724-3734. https:// doi.org/10.1182/blood-2010-05-282632

28. Cook MB, Dawsey SM, Freedman ND, et al. Sex disparities in cancer incidence by period and age. Cancer Epidemiol Prev Biomark 2009;18(4):1174-1182. https://doi.org/10.1158/1055-9965.EPI-08-1118

29. Statistics South Africa. Mining: A brief history. 2017. http://www.statssa.gov.za/? $\mathrm{p}=9720$ (accessed 6 April 2018).

30. Statistics South Africa. Mining industry, 2015. Pretoria: Stats SA, 2017. http://www.statssa.gov.za/ publications/Report-20-01-02/Report-20-01-022015.pdf (accessed 6 April 2018).

31. Mogongoa LF, Brand CE, De Jager L, Ekosse GE. Haematological and iron status of Qwa Qwa women Mogongoa LF, Brand CE, De Jager L, Ekosse GE. Haematological and iron status of Qwa Qwa women
in South Africa who ingest clays. Med Technol SA 2011;25(1):33-37. https://journals.co.za/content/ in South Africa who ingest clays. Med Technol SA
medtech/25/1/EJC74255 (accessed 4 April 2019).

32. Rose EA, Porcerelli JH, Neale AV. Pica: Common but commonly missed. J Am Board Fam Pract Rose EA, Porcerelli JH, Neale AV. Pica: Common but commonly missed. J Am Board Fam Pract
2000;13(5):353-358. http://www.jabfm.org/content/13/5/353.full.pdf+html (accessed 17 March 2019). 2000;13(5):353-358. http://www.jabfm.org/content/13/5/353.full.pdf + html (accessed 17 March 2019). Macheka L, Olowoyo J, Matsela L, Khine A. Prevalence of geophagia and its contributing factors among
pregnant women at Dr. George Mukhari Academic Hospital, Pretoria. Afr Health Sci 2016;16(4):972pregnant women at Dr. George Mukhari
978. https://doi.org/10.4314/ahs.v16i4.13

34. George G, Ndip NE. Prevalence of geophagia and its possible implications to health - a study in rural South Africa. 2011 2nd International Conference on Environmental Science and Development. IPCBEE 2011;4:166-169. https://pdfs.semanticscholar.org/9b1f/lef77709cc0821ffb9df6616ef4871dd 9ca.pdf (accessed 4 April 2019).

35. Winde F, Erasmus E, Geipel G. Uranium contaminated drinking water linked to leukaemia - revisiting a case study from South Africa taking alternative exposure pathways into account. Sci Total Environ 2017;574(1 January):400-421. https://doi.org/10.1016/j.scitotenv.2016.09.035

36. Winde F, Sandham LA. Uranium pollution of South African streams - an overview of the situation in gold mining areas of the Witwatersrand. GeoJournal 2004;61(2):131-149. https://doi.org/10.1007/ s10708-004-2867-4

37. Winde F. Uranium pollution of the Wonderfonteinspruit, 1997 - 2008. Part 2: Uranium in water concentrations, loads and associated risks. Water SA 2010;36(3):257-278. http://www.scielo.org.za/ pdf/wsa/v36n3/a07v36n3.pdf (accessed 17 March 2019).

38. Winde F. Uranium pollution in South Africa: Past research and future needs. February 2016. https:// www.researchgate.net/publication/297764951_Uranium_pollution_in_South_Africa_Past_research and_future_needs (accessed 17 March 2019).

39. Toens PD, Stadler W, Wullschleger NJ. The association of groundwater chemistry and geology with atypical lymphocytes (as a biological indicator) in the Pofadder area, north western Cape, South atypical lymphocytes (as a biological indicator) in the Pofadder area, north western Cape, South
Africa. http://www.wrc.org.za/wp-content/uploads/mdocs/839-1-98.pdf (accessed 17 March 2019).

40. Kamunda C, Mathuthu M, Madhuku M. An assessment of radiological hazards from gold mine tailings Kamunda C, Mathuthu M, Madhuku M. An assessment of radiological hazards from gold mine tailings
in the province of Gauteng in South Africa. Int J Environ Res Public Health 2016;13(1):138. https:// in the province of Gauteng in Sor
doi.org/10.3390/ijerph13010138

41. Winde F Hoffmann E Virtual Geographical Environments as a tool to map human exposure to Winde F, Hoffmann E. Virtual Geographical Environments as a tool to map human exposure to
mining-related radionuclides. In: Merkel B, Arab A, eds. Uranium - Past and Future Challenges. Cham, Switzerland: Springer, 2015. https://doi.org/10.1007/978-3-319-11059-2_23

Accepted 21 September 2018. 